\title{
VALOR E LIMITES DA CAUSALIDADE EM SCHLICK: SENTIDO E APLICAÇÕES
}

\section{VALUE AND THE LIMITS OF CAUSALITY IN SCHLICK: MEANING AND APPLICATIONS}

\author{
Ramiro Délio Borges de Meneses* \\ Centro de Estudos Filosóficos da Faculdade de Filosofia de Braga \\ Universidade Católica Portuguesa
}

RESUMO: Com a física moderna, particularmente pela criação da Mecânica Quântica,M. Schlick apresentou uma nova crítica, no âmbito do neopositivismo, sobre o princípio de causalidade.

PALAVRAS-CHAVE: Schlick,causalidade,sentido,evolução e leis da física.

ABSTRACT: With modern physics and especially with the creation of quantum mechanics, M. Schlick presents a new criticism of the principle of causality in the sphere of neopositivism.

KEYWORDS: Schlick, values, limits, causality, laws of physics, meaning, and applications.

\section{Introdução}

A revolução, operada pela Física Quântica, chegou, no que concerne ao problema da causalidade.e constituiu algo que era preciso prever.

Por mais que se tenha filosofado acerca do determinismo e do indeterminismo, sobre o conteúdo, a validade e a verificação do princípio da causalidade, a

\footnotetext{
*E-mail: borges272@gmail.com
} 
ninguém ocorreu a possibilidade ,que determina a física dos quanta, dando-nos a chave que nos capacita para compreender o grau de ordem causal ,realmente existente na realidade.

Mais tarde, refere M. Schlick, reconheceu-se em que ponto as novas ideias divergem das antigas.

Neste momento, após demonstrada a fecundidade da teoria dos quanta, $(\varepsilon=h \cdot v)$, em virtude dos êxitos extraordinários, derivados da sua aplicação e havendo-nos já familiarizado com as novas ideias, já não se pode considerar prematura a tentativa de obter uma clareza filosófica, acerca do sentido e do alcance da contribuição que a física actual traz para a compreensão da causalidade. ${ }^{1}$

Naturalmente, cabe verificar aquilo que o pesquisador da natureza entende por causalidade. A causalidade não passa de uma palavra para designar a existência de uma lei.

O princípio da causalidade será constituído, manifestamente,pela afirmação de que tudo no Universo sucede segundo a lei.

Será, segundo Schlick, uma e mesma coisa afirmar a validade do princípio da causalidade ou a existência do determinismo.

Para formular o enunciado causal ou a tese determinística, impõe-se previamente definir o que se deverá entender por lei natural ou por dependência recíproca entre acontecimentos e a natureza ${ }^{2}$.

Somente depois de esclarecidos sobre o referido ponto, poderemos compreender o sentido do determinismo, ao afirmar que todo o acontecimento será membro de uma relação causal e que todo o acontecimento na sua totalidade, depende de outros processos.

\footnotetext{
${ }^{1}$ Cf. M. Schlick - «Die Kausalitaet in der gegenwartigen Physik», in: Naturwissenschaften, 19 (Berlin, 1931) 145-146.

${ }^{2}$ Cf. Ibidem, 146-147.
} 
Em consequência disto, distinguimos, em todo o caso, o problema da significação da palavra «causalidade» ou lei da natureza física, da questão da validade do princípio causal ou do enunciado causal, ocupando-nos exclusivamente da primeira questão.

No mencionado contexto, Reichenbach fala do destino das duas formas de hipótese causal. A primeira denomina-a «forma de implicação» (Implikationsform), porque ocorre, no dizer do lógico e filósofo, quando a Física estabelece ou formula enunciados deste tipo: se ocorrer A, então ocorrerá B.

A segunda é a forma de determinação da hipótese causal e identifica-se com o determinismo, o qual afirma que o decurso do mundo, como um todo, permanece inalterável, de tal maneira que o passado e o futuro serão determinados com secção do Universo quadridimensional.

Schlick considerou mais acertado caracterizar a mencionada diferença como distinção entre o conceito causal e o princípio de causalidade.

Trata-se, pois, de analisar o conteúdo ou significado do princípio de causalidade. Assim o faremos, segundo o pensamento de M. Schlick, terminando com uma reflexão crítica pessoal sobre o sentido da causalidade segundo o «neopositivismo lógico", repensado por um dos seus co-fundadores.

\section{Sentido e valor das Leis da Física}

$\mathrm{Na}$ linguagem da física, qualquer acontecimento descreve-se como discurso de determinadas grandezas,como se poderá testemunhar pelo seguinte enunciado dedutivo, que vai de Einstein a Newton, pela energia cinética:

$$
E_{k}=m c^{2}\left(1+1 / 2 v^{2} / c^{2}+\ldots-1\right)=1 / 2 m \cdot v^{2}
$$

Ou o «valor métrico» de uma constante da física:

$$
h=6,626 \times 10^{-34} \mathrm{~J} \cdot \mathrm{s} \text { ou } \mathrm{c}=2,998 \times 10^{8} \mathrm{~m} / \mathrm{s} . \quad 3
$$

\footnotetext{
${ }^{3}$ Cf. P. A. Tipler - Física Moderna, tradução do inglês, Rio de Janeiro, Editora Guamabara, 1981, 25.
} 
A partir daqui observamos que, no referido discurso físico-matemático, será possível medir um número finito de valores, que a experiência fornece apenas numa variedade limitada de números de observação, sendo cada valor caracterizado por uma certa imprecisão, quer entre variáveis, $(\overrightarrow{\mathrm{F}}=\mathrm{m} \cdot \overrightarrow{\mathrm{a}})$ quer entre constantes $\left(K=R / N=8,617 \times 10^{5} \mathrm{~V} / K\right)$.

Como deve ser a série, para que possamos dizer que ela representa um discurso ou uma expressão natural e que existe um nexo causal entre as grandezas calculadas e as observadas?

Naturalmente que todo o valor da grandeza se refere a determinado ponto do espaço e do tempo. Há uma ligação, na lei, entre as grandezas espacio-temporais, como se vê na lei fundamental da Dinâmica de Newton:

$$
(\vec{F}=m \cdot \vec{v} / t=m \cdot \vec{a}) \quad 4
$$

Somente, através de reflexões causais, chegamos a dar aos conhecimentos o seu lugar definitivo nas realidades físicas pelo espaço-tempo, enquanto, partindo das realidades fenoménicas espacio-temporais, fazemos a transição para o mundo físico.

Segundo Schlick, existe a pressuposição de que ocorrem na natureza «qualidades», no sentido de que diferentes áreas do mundo são comparáveis entre si, de sorte que podemos afirmar: a mesma grandeza, que, neste lugar, tem o valor $\mathrm{t}$, apresenta naquele outro o valor $\mathrm{t}$. Daqui se aufere que a comparabilidade das medidas é pré-condição para a mensurabilidade, tal como se observa com as «constantes» da física, como exemplo:

$$
N a=6,023 \times 10^{25} \text { partículas } / \text { mol }
$$

À luz das observações que acabamos de fazer, o nosso problema do conteúdo ou sentido do conceito de «causalidade» reduz-se à seguinte questão: que propriedade deve apresentar a multidão, ou série de grandezas ordenadas no espaço e no tempo, para que possa ser entendida como expressão de uma lei natural?

\footnotetext{
${ }^{4}$ Cf. J. Synge; B. A. Griffith - Mecânica Racional, tradução do inglês, Rio de Janeiro, Editora Globo, 1960, 143-145.
} 
Esta propriedade não pode ser outra coisa senão uma ordenação ou disposição ,uma vez que os acontecimentos já estão ordenados extensivamente no espaço e no tempo, como espécie de ordenação ou disposição mais intensiva ${ }^{5}$. Assim se poderá encontrar nas grandezas vectoriais da Mecânica:

$$
\vec{a}=\vec{v} / t ; \vec{v}=\vec{r} / t
$$

Esta ordenação efectuar-se, na direcção temporal, uma vez que não falamos de causalidade, sempre que se trate de uma ordenação espacial. As regularidades em sentido espacial, se as houvesse ,denominar-se-iam «leis de coexistência».

Toda e qualquer ordem de acontecimentos, no sentido temporal, deve ser entendida como relação causal. Somente o caos e a irregularidade absoluta poderiam ser caracterizadas como acontecimento causal, como mero acaso em qualquer vestígio de uma ordem que já denotaria a causalidade.

$\mathrm{O}$ uso do termo - causal - oferece a vantagem de uma proximidade maior à linguagem natural, do que se reduzirmos o termo a uma ordem, que poderíamos denominar - causalidade total -, mas que se tenciona afirmar algo como facto de o acontecimento considerado ser totalmente determinado.

Se quiséssemos restringir a significação da palavra à causalidade completa, então não encontraríamos, na natureza, qualquer aplicação para ela, quando encontramos a existência da causalidade, como facto inegável da experiência.

Segundo Schlick, a causalidade identifica-se com a ordem, enquanto que a desordem identifica-se com a irregularidade. Assim se verifica na função de Boltzmann para a «entropia»:

$$
\mathrm{S}=k \cdot \ln W n
$$

Qualquer acontecimento natural, descrito por uma série de valores de grandezas, escalares e ou vectoriais, refere-se como "causal», se esses valores apresen-

\footnotetext{
${ }^{5}$ Cf. L. D. Kudriávisev - Curso de Análise Matemática, 1, tradução do russo, Editorial Mir, 1983, 15-22.
} 
tarem alguma ordenação na coordenada fluente do tempo (t). Uma tal definição somente adquirirá sentido, se soubermos o que se entende por ordem, segundo a perspectiva de Schlick ${ }^{6}$.

\section{Da ordem à regularidade}

Tanto na vida, como na ciência, fazemos uma distinção clara entre a ordem e a desordem,lbem como entre a regularidade e a irregularidade.

Segundo Schlick, será fundamental verificar como é que a física define as leis da natureza e de que modo descreve a interdependência existente entre os acontecimentos. Esta elabora a função matemática. A dependência de um acontecimento, em relação a outros, exprime-se pelo facto de os valores de uma parte das grandezas de estado serem representadas como funções da natureza:

$$
Q=U+T ; S=Q / T
$$

Toda a ordem de número será representada por uma função, como acontece, por exemplo, em Análise Matemática:

$$
\begin{array}{r}
\int f(x) \cdot d x=F^{\prime}(x)+C \\
\frac{d F(x)}{d x} \cdot=f(x)^{7}
\end{array}
$$

Assim parecerá que a característica da ordem teria a capacidade ou possibilidade de ser expressa por uma função, como acontece com o cálculo integral aplicado à física clássica:

$$
\begin{gathered}
\int d p=\int m \cdot d v \\
p=m \int d v ; p=m \cdot v
\end{gathered}
$$

\footnotetext{
${ }^{6}$ Cf. K. Huang - Statistical Mechanics, second edition, J. Wiley and Sons, New York, 1987, 60-62.

${ }^{7}$ Cf. F. Ayres - Cálculo Diferencial e Integral, tradução do inglês, S. Paulo, McGraw Hill, 1991, 125.
} 
Ou no caso da «energia cinética», teremos:

$$
\begin{gathered}
\int d E_{c}=\int m \cdot v \cdot d v \\
E=m \int v \cdot d v \\
E=m \cdot 1 / 2 \cdot v^{2}+\mathrm{C} ; \mathrm{E}_{\mathrm{c}}=1 / 2 m v^{2}
\end{gathered}
$$

Contudo, parece que, sempre que no momento em que se formula esse conceito de identidade de função e da lei, observamos ser possível admitir ,que tal conceito seja correcto.

Qualquer que seja a distribuição das grandezas dadas, será sempre possível encontrar funções que representem esta distribuição com a exactidão que se deseja.

Isto quer dizer que toda a distribuição das grandezas deveria ser considerada como uma "ordem». Não restaria outra alternativa senão formular determinadas exigências, quanto às funções que descrevem sequências de valores, procurando, através destas exigências, definir o conceito de ordem. Aqui temos elementos da análise de M. Schlick.

Segundo Maxwell, nas funções que descrevem o decurso do acontecimento físico, as coordenadas de função e de tempo não podem ocorrer explicitamente. Esta exigência física equivale ao conceito que a linguagem popular exprime na proposição seguinte: a causas iguais correspondem efeitos iguais.

Esta proporção parece existir na equação geral do campo electromagnético:

$$
\vec{E} \cdot \vec{H}=\vec{S}
$$

A referida concepção significa que um processo ,que decorre, no espaço e no tempo, para as mesmas condições, decorrerá da mesma forma em qualquer outro lugar e em qualquer outro tempo ${ }^{8}$.

${ }^{8}$ Cf., A. N. Matveyev; L. F. Landoviitz - Principles of Electrodynamics, New York, Reinhold Publishing, 1966, 5-10. 
Segundo Schlick, a validade geral é exactamente aquilo que nas leis da física se exprime com o termo de "necessidade», e, assim, pareceria que a característica da relação causal seria idêntica para esta determinação. Nas leis da física, estas exigências são para se cumprir.

Se o espaço e o tempo ocorressem explicitamente nas equações físicas, então teriam um significado completamente diverso, daquele que é próprio no nosso mundo e estaria liquidada a relatividade do espaço e do tempo, tão fundamentais para a nossa cosmovisão. Assim, o espaço e o tempo já não poderiam desempenhar a função de formas dos acontecimentos.

O ponto decisivo, no referido caso, parece ser o facto de que podemos levar em conta a influência do espaço e do tempo com tanta facilidade, que esses dois factores entram de maneira tão fácil nas fórmulas da Mecânica, como se pode observar pelo teorema da variação da quantidade de movimento do ponto material:

$$
\mathrm{m} \cdot \vec{v}-m \overrightarrow{v_{0}}=\int_{0}^{t} \vec{F} \cdot d t
$$

O incremento do vector da quantidade de movimento, do ponto material (em forma vectorial), durante certo intervalo de tempo é igual ao vector do impulso da força, durante esse mesmo intervalo de tempo.

O mesmo se passa com a física atómica, onde, por exemplo, a carga dos electróes se comporta, de modo diverso cada semana e a cada hora, e se decorresse numa curva inteiramente irregular. Poderemos representar a sua dependência em relação ao tempo através de uma função. Neste caso, diríamos que não há nenhuma regularidade natural, senão que as oscilações da grandeza seriam regidas pelo acaso.

Os processos descontínuos no átomo, que a teoria de Bohr interpretou como saltos de um electrão, de uma via para a outra, são concebidos como puramente causais, como "destituídos de causa», embora possamos registar a sua ocorrência, em função do tempo $(\mathrm{t})$.

Esta função seria complicada, não periódica, não previsível e somente, por esta razão ,afirmamos não haver regularidade. 
Para Schlick, poderia parecer que falamos de ordem, de lei e causalidade, todas as vezes que o decurso dos fenómenos fosse descrito por funçôes, de forma mais simples, enquanto que a complexidade da fórmula seria a característica da falta de ordem, da ausência de lei e de acaso. Assim, parece chegar-se, com muita facilidade, a definir a causalidade pela simplicidade das funções descritivas.

Todo o pesquisador ,que consegue representar uma série de observações por uma fórmula muito simples - função linear quadrada ou exponencial - ,tem imediatamente a certeza de haver descoberto uma lei, como se vê:

$$
T=1 / 2 m v^{2}
$$

Ou a «potência» de uma força:

$$
N=\frac{d \mathrm{~A}}{d t},
$$

Igualmente ,a definição de Maxwell também aponta uma característica da causalidade, a qual se considera como critério decisivo.

É certo que não se pode definir o conceito de simplicidade de outra forma, senão por uma convenção, que necessariamente permanecerá sempre arbitrária.

Sem dúvida, estaremos propensos a considerar uma função de primeiro grau, mais simples do que uma de segundo grau.Todavia, também a segunda, representa ,sem dúvida, uma lei certa, quando descreve os dados da observação com ampla exactidão, precisamente a fórmula da gravitação de Newton:

$$
\vec{F}=G \cdot \frac{m \cdot M}{d^{2}} \cdot=\vec{r} \quad 10
$$

na qual ocorre o "quadrado da distância», geralmente é considerada como exemplo clássico de uma lei natural simples.

\footnotetext{
${ }^{9}$ Cf. A. N. Matveyev; L. F. Landoviitz - Principles of Electrodynamics, New York, Reinhold Publishing, 1966, 5-10, 1965, 27-30.

${ }^{10}$ Cf. C. L. Siegel - Curso de Mecânica Celeste, tradução do alemão, Lisboa, Fundação Calouste Gulbenkian, 1965, 10-26.
} 
Além disso, pode-se, por exemplo, concordar em que atravessam um número pré-determinado de pontos com suficiente aproximação, ao considerar ,como a mais simples, aquela que ,em média, em toda a parte, apresenta maior raio de curvatura.

A situação é ainda pior, pelo facto de que o que interessa não é, em absoluto, a simplicidade de uma lei natural isolada, mas antes a simplicidade do sistema global de todas as leis da física.

Com efeito, a verdadeira equação de estado dos gases, de forma alguma ,apresenta a forma simples de Boyle-Mariotte:

$$
\begin{gathered}
P V / T=P_{0} V_{0} / T_{0}{ }^{11} \\
P \cdot V=T \text { const. }
\end{gathered}
$$

Contudo, sabemos que a sua forma complicada pode ser explicada por meio de um sistema particularmente simples de leis elementares. Em princípio, seria ainda muito mais difícil encontrar regras para a simplicidade de um sistema de fórmulas. Tais normas conservariam um carácter provisório, de sorte que a ordem aparente se manifestaria como desordem, à medida em que progride o conhecimento.

Ao que parece, nem o critério de Maxwell proporciona uma resposta satisfatória à questão da definição de causalidade. $\mathrm{O}$ primeiro evidencia-se como restrito e o segundo excessivamente vago.

Imaginemos que, num sistema físico, durante um determinado tempo, as grandezas de estado, para a maioria dos pontos do seu interior , estão bem determinadas. Costuma-se dizer que o princípio de causalidade vale, quando é possível, a partir do estado do sistema, durante um tempo, muito reduzido, e a partir de condições limite. Com efeito, as funções são escolhidas de modo a representar,tudo aquilo que se observa no sistema.

${ }^{11}$ Cf. N. Glinka - Quimica Geral, tradução do russo, 1 volume, Moscovo, Editora Mir, 29. 
Se acrescentarmos as condições de que as equações usadas não devem conter explicitamente as coordenadas de espaço e de tempo, então devem ser muito simples.

Não devemos formular a diferença entre o caos e o cosmos, no sentido de que o primeiro só seria acessível.

Mas,acrescentamos as condições de que as equações empregues não devem conter explicitamente as coordenadas de espaço e tempo ${ }^{12}$.

Certamente, segundo Schlick, não queremos formular a diferença entre o «caos» e o «cosmos», no sentido em que o primeiro só seria acessível a um exímio matemático, ao passo que a segunda o seria, também, a um matemático mediano.

Após termos conseguido encontrar uma função, que liga e confirma satisfatoriamente, entre si ,uma série de resultados de observação, ainda não estamos em absoluto satisfeitos.

Para o físico, na sua qualidade de pesquisador da realidade, este é o único elemento importante, decisivo e essencial, ou seja, que as equações, deduzidas de dados concretos, se verifiquem no caso de novos dados, somente quando ocorre isto, considera-se a fórmula como lei da natureza.

Schlick afirma que o verdadeiro critério da regularidade natural, como característica essencial da causalidade, consiste no facto de as previsões feitas se cumprirem.

Para Schlick, o cumprimento de uma previsão deve-se entender pelo facto de uma fórmula se comprovar correctamente, para aqueles dados,. que não foram usados na formulação da mesma.

É evidente que a verificação de uma lei só pode ocorrer depois de esta ser estabelecida, porém isto não significa uma característica ou privilégio do futuro.

${ }^{12}$ Cf. M. Schlick - «Die Kausalitaet in der gegenwartigen Physik», in: Naturwissenschaften, 19 (Berlin, 1931) 148. 
O essencial será notar que é indiferente, se os dados verificados pertencem ao passado ou ao futuro. É irrelevante o momento em que são conhecidos ou são utilizados para a comprovação. A confirmação permanece a mesma, tanto na eventualidade de um dado já ser conhecido antes de se formular uma teoria, como a anomalia do movimento de Mercúrio , como no caso de o dado ser profetizado pela teoria, como acontece com o deslocamento das linhas do espectro para o vermelho, no caso da lei de Hubble (velocidade de fuga galáctica):

$$
V_{g}=H \cdot r
$$

Se somos capazes de predizer correctamente novas observações ,então é totalmente indiferente a estrutura das fórmulas, ou seja, se se apresentam simples ou complexas e se o espaço e o tempo aparecem explicitamente ou não.

No momento em que alguém poder calcular os novos dados de observação, a partir dos antigos, haveremos de reconhecer que tal pessoa enxergou o carácter da lei natural, inerente a tais processos. O facto de se predizer constitui uma característica suficiente da causalidade.

No pensamento de Schlick, parece haver uma segunda alternativa, onde a lei foi válida durante a única série de observaçôes, depois disto deixou de existir na realidade. É óbvio que esta explicação constituiria um outro modo de expressar o facto ,de que, no caso, não existe uma lei natural. A validade universal da lei da física seria negada.

Daqui se infere que a confirmação das previsões constitui o único critério da causalidade e que somente através dela é que a realidade nos fala ${ }^{13}$.

Fundamentalmente, a confirmação de uma previsão jamais demonstra a existência da "causalidade», senão que apenas a torna "provável». Observações posteriores podem ocorrer, desmentindo a presumível lei, e, neste caso ,deveríamos afirmar que a lei se monstrou como acertada.Uma verificação definitiva é impossível. Daqui que uma afirmação causal, logicamente, não tem o carácter de um 16-39.

${ }^{13}$ Cf. M. Schlick - «Ueber das Fundament der Erkenntnis», in: Erkenntnis, 4 (Leipzig, 1934) 
enunciado, uma vez que um enunciado autêntico deve poder ser definitivamente verificado.

Assim, será impossível definir a causalidade, se por ela entendermos que tratando-se de um processo pré-indicado, seria possível responder à pergunta: o processo foi causal ou não?

Somente em relação ao caso individual, ou seja, em relação à verificação individual, poderemos dizer: o processo ocorreu conforme as exigências da causalidade.

Isto será inteiramente suficiente para o progresso do conhecimento da natureza. Se algumas verificações tiveram êxito, concluiremos com segurança sobre a lei verificada, com aquela certeza, em virtude da qual sem objecçôes, confiamos a nossa vida a um motor construído, segundo as leis da natureza ${ }^{14}$.

As circunstâncias acima referidas significam que uma lei da física não apresenta o carácter lógico de um enunciado, mas antes traduz uma indicação para a formulação de enunciados, que Schlick bebeu do pensamento lógico-filosófico de L. Wittgenstein.

Segundo Schlick, uma afirmação causal é idêntica a uma lei. Naturalmente, a afirmação de que o princípio da energia expressa, nem mais nem menos, aquilo que o próprio princípio da energia afirma:

$$
\begin{gathered}
T=1 / 2 \sum \Delta m v=1 / 2 \sum \Delta m(w h)^{2}=1 / 2 w^{2} \sum \Delta m h^{2} ; \\
T=1 / 2 J_{2} \cdot w^{2}
\end{gathered}
$$

A energia cinética de um corpo sólido, que gira em torno de um eixo fixo, será igual ao semiproduto do momento de inércia do corpo, relativamente ao eixo de rotação, pelo quadrado da velocidade angular ${ }^{15}$.

${ }^{14}$ Cf. R. D. Borges De Meneses - «Determinismo e Indeterminismo:uma ponte entre a física e a filosofia»,in : Estudos Teológicos,12(Coimbra,2005),78-90.

${ }^{15}$ Cf. V. M. Starzhinski - Mecânica Teórica, tradução do russo, Moscou, Editorial Mir, 1985, 400-402. 
Como somente são verificáveis os enunciados individuais, que se deduzem de uma lei natural, apresentam-se numa das seguintes formulações: num triângulo rectângulo (circunstância métrica) ,o quadrado da hipotenusa será igual à soma dos quadrados dos catetos (em forma trigonométrica):

$$
\cos ^{2} \alpha .+\operatorname{sen}^{2} \alpha .=1
$$

Naturalmente, a verificação e a confirmação de uma previsão e a comprovação pela experiência constituem o verdadeiro critério da causalidade e ,num sentido prático, o único em que se poderá falar da verificação de uma lei. Neste aspecto, a causalidade é verificável ${ }^{16}$.

\section{A teoria dos «quanta» a causalidade}

Se os físicos afirmam que a validade do princípio de causalidade é inconciliável com a teoria dos quanta de M. Planck $(\varepsilon=h v)$,então o sentido desta asserção reside no facto de que a referida teoria torna impossível "previsões exactas».

Também á física atómica é permitido afirmar que todo o sistema de protões e de electrôes ,e o seu estado, é determinado, em cada momento, se o espaço e o impulso de todas as partículas.se verificar. Na Mecânica Quântica ,deduz-se uma determinada fórmula (relação de incerteza de Heisenberg):

$$
\begin{gathered}
\Delta x \cdot \Delta p-\hbar ; \Delta E \cdot \Delta t-\hbar \\
\Delta x \cdot \Delta p \frac{\lambda}{2 \operatorname{sen} \theta} \cdot \frac{h \cdot \operatorname{sen} \theta}{\lambda}=1 / 2 h,
\end{gathered}
$$

a qual ensina ser impossível indicar com absoluta exactidão, para uma partícula, ambos os elementos, ou seja, o lugar e a velocidade, senão que, com quanto maior precisão ,se fixar o valor de uma coordenada, tanto maior será a inexactidão,com a qual se deve contar.

${ }^{16}$ Cf. M. Schlick - «Die Kausalitaet in der gegenwartigen Physik», in: Naturwissenschaften, 19 (Berlin, 1931) 148-150. 
Se, por exemplo, soubermos que a coordenada do lugar está dentro de um pequeno intervalo $\Delta p$, a coordenada da velocidade q só pode ser indicada com grau de exactidão, tal que o seu valor permanece indeterminado, até a um intervalo $\Delta q$, e isto de tal forma que o produto $\Delta p \cdot \Delta q$ é da ordem de grandeza da constante h. Em princípio, seria possível determinar uma das duas coordenadas com toda a "precisão", porém a sua observação exacta ,teria como consequência que, a respeito da outra coordenada,não seríamos capazes de dizer «absolutamente nada $»^{17}$.

Se, por exemplo, imaginamos,como determinado pela observação, o lugar de um electrão, com uma imprecisão, que significa quando afirmo que só é possível indicar a direcção da velocidade deste electrão ,com uma exactidão $\Delta \theta$ ?

Quando uma partícula voa em determinada direcção, só então será possível verificar pelo facto da mesma ter chegado a um determinado ponto. Determinar a velocidade de uma partícula não significa em absoluto outra coisa sendo predizer que após um certo período de tempo chegará a um determinado ponto.

Se o lugar dos corpúsculos fosse observado com exactidão absoluta, teria isto como consequência que um princípio não mais saberíamos em que direcção se poderia encontrar o electrão depois de um breve período de tempo. Somente a observação posterior poderia indicar, sendo que repetindo-se muitas vezes a mesma experiência, manifestar-se-ia que, na prática, a direcção é desconhecida ${ }^{18}$.

Nesta linha de pensamento, alega-se, que uma vez que o princípio da causalidade afirma que os estudos futuros do sistema são determinados pelo seu estudo inicial, o citado princípio pressupóe que o estado inicial pode ser indicado com exactidão,então a causalidade cai por terra, pois esta pressuposição não se verifica.

Contudo, o importante é que se perceba o seguinte: a incerteza ou indeterminação de que se fala ,na relação de Heisenberg,será, na verdade, uma incerte-

${ }^{17}$ Cf. W. Heisenberg - Die physikalischen Prinzipien der Quantentheorie, Mannheim, Bibliographischen Institut, 1958, 15-19.

${ }^{18}$ Cf. R. Feynman - La nature de la physique, tradução do inglês, Éditions du Seuil, 1980, 181186. 
za de previsão.

A Física dos quanta vê o critério da causalidade precisamente onde também nós o descobrimos e que é a única razão, que leva esta física a considerar como falha o princípio da causalidade, na impossibilidade de se fazer previsões absolutamente exactas ${ }^{19}$.

Segundo M. Born, surge a impossibilidade de medir todos os dados de um estado, que nos impede de predeterminar o decurso ulterior. Com isto, o princípio de causalidade perderia todo o seu sentido, se entendido na acepção habitual.

Se é impossível conhecer todas as condições (causas) de um processo ou acontecimento, então não passará de palavreado afirmar que todo o acontecimento tem uma causa.

A grande contribuição oferecida pela física dos quanta,para o problema da causalidade, não reside em negar-se, segundo Schlick, a validade do enunciado causal, nem no facto de que a descrição da microestrutura da natureza se faria mediante regularidades estatísticas, ao invés de regularidades causais, nem mesmo no facto de que o haver-se compreendido, que as leis naturais apresentam uma validade provável.

A novidade trazida, pela física moderna, consiste na descoberta, até então nunca suspeitada, de que as próprias leis da natureza colocam, em princípio, um limite à exactidão das previsões. Isto é totalmente diverso da asserção de que existe realmente e na prática um limite para a exactidão das observações e de que a aceitação das leis da física, absolutamente exactas é, em todo o caso, dispensável, se quisermos levar em conta todas as experiências.

Antigamente havia a impressão de que o problema do determinismo permaneceria sem solução. Logo, a maneira actual de o solucionar seria mediante uma lei da física , pela relação de Heisenberg ,o que não tinha sido previsto.

${ }^{19}$ Cf. M. Schlick - «Positivismus und Realismus», in: Erkenntnis, 3 (Leipzig, 1932) 102-116. 
$\mathrm{Na}$ estrutura da teoria dos quanta $(\varepsilon=h v)$, a relação de indeterminação constitui uma parte integrante e devemos confiar na sua rectidão,até ao momento em que novas experiências e observações obriguem a uma revisão da teoria quântica ${ }^{20}$.

Naturalmente que na área dos princípios, o progresso é manifesto e poderemos falar de verificação empírica do princípio de causalidade, no mesmo sentido que haja uma verificação de qualquer lei específica.

\section{Falsidade da proposição causal na Teoria Quântica}

Bergmann e Vogel supõem com razão que os físicos, que rejeitam o princípio da causalidade, fundamentalmente partiram da posição experimental. Ambos partilham da opinião de Heisenberg (uma vez que todas as experiências estão sujeitas às leis da Mecânica dos Quantae e deve-se concluir que esta Mecânica verificou, com carácter definitivo, que a lei da causalidade não é válida), que se não pode afirmar que a teoria dos quanta demonstrou a falsidade do princípio da causalidade. Ambos enfatizam, com insistência, que a proposição causal não será, nem confirmada nem refutada pela experiência.

Segundo Bergmann, o motivo, pelo qual a proposição causal não pode ser refutada nem confirmada, reside no facto de a considerar como juízo sintético $a$ priori, na acepção de Kant. Como é sabido, um tal juízo deve exprimir um autêntico conhecimento. Mas deve estar subtraído a qualquer verificação pela experiência, dado que precisamente tal juízo constitui a base para a possibilidade da experiência. Se uma proposição disser alguma coisa acerca da realidade deverá ser possível, mediante a observação da realidade,então verificar se a proposição é verdadeira ou falsa. Se, por princípio, não existir tal possibilidade de verificação, deve-se afirmar que uma tal proposição nada diz e é inexpressiva, não se podendo encerrar nenhum conhecimento sobre a natureza.

Consequentemente , dizer que uma proposição não é verificável, pela expe-

${ }^{20}$ Cf. M. Schlick - «Die Kausalitaet in der gegenwartigen Physik», in: Naturwissenschaften, 19 (Berlin, 1931) 149-151. 
riência, equivale a afirmar o seguinte: a aparência e a realidade do mundo são independentes da verdade ou da falsidade de proposiçóes e, por conseguinte, esta nada diz sobre ela. Kant acreditava que a proposição causal diz muito sobre o mundo empírico e até determina o seu carácter ${ }^{21}$.

Os resultados da Mecânica Quântica obrigarão a concluir sobre a falsidade do princípio de causalidade? Ou a conclusão a ser tirada será que ele nada diz?

Embora ,o princípio de causalidade apresenta-se gramaticalmente sob a forma de proposição enunciativa, sabemos pela Lógica Simbólica que, pela forma externa de uma proposição, muito pouco se pode concluir quanto à sua verdadeira forma lógica e seria muito possível que,por trás da forma categórica do princípio de causalidade, se esconda uma espécie de «ordem», uma exigência, mais ou menos aquilo que Kant denominou como "princípio regulador».

Por tudo quanto foi dito, deveremos escolher entre as três possibilidades:

- O princípio de causalidade é uma tautologia, sendo sempre verdadeiro para todos os casos (semântica), mas inexpressivo;

- O princípio de causalidade é uma proposiçāo empírica, surgindo como verdadeiro ou falso;

- O princípio de causalidade apresenta-se como "postulado", como uma obrigação para continuar a procurar causas e efeitos. Assim examinaremos as anteriores formulações.

5.1. Uma proposição causal na forma - todo o acontecimento decorre segundo a lei- é certamente "tautológico» se por "segundo a lei» se entender como responsável por alguma fórmula. Não pode ser este o verdadeiro conteúdo ou sentido do princípio, surgindo uma nova formulação.

${ }^{21}$ Cf. R. D. Borges De Meneses - «Teoria do Juízo em Kant», in: Humanistica e Teologia, 23(Porto, 2002),209-226. 
Se o princípio de causalidade tivesse uma característica "tautológica»,então o determinismo seria evidente, mas vazio de sentido. O seu oposto, que é o indeterminismo seria per se contraditório. A negação de uma tautologia origina uma contradição.

Para se saber se uma proposição é tautológica ou não, não carece evidentemente de nenhuma experiência, mas basta ter presente apenas o seu sentido. Se alguém pretendesse que a física demonstre o carácter tautológico do enunciado causal, então esta afirmação seria sem sentido, tal como dizer que $2+2=4$, segundo a Aritmética.

Mas, uma vez que a física actual, em todo o caso, nos ensina algo acerca da validade do princípio de causalidade, este princípio não pode ser uma frase vazia, uma tautologia, uma convenção, mas deve ter um tal carácter, que, de alguma forma ,esteja submetido ao juízo da experiência.

5.2. Embora Heisenberg fale da não validade da proposição causal, Born fala da ausência de sentido.

Segundo as reflexões de Schlick, o sentido do princípio poderia ser expresso na seguinte formulação: todos os acontecimentos são, por princípio, passíveis de previsão.

Se esta proposição representar um verdadeiro enunciado,logo a sua verdade é verificável, mas poderemos afirmar que a sua verificação já foi feita e até o momento foi negativo.

Segundo Schlick, qualifica-se como "previsto» um acontecimento, quando o mesmo foi deduzido com o auxílio de uma fórmula, a qual foi elaborada com base numa série de observações de outros acontecimentos.

A negação da possibilidade de "prever» com exactidão, defendida pela teoria dos quanta, significaria que é impossível deduzir de uma série de dados de observação uma fórmula, que, por sua vez, represente com exactidão novos dados de observação.

Sempre que se encontre posteriormente uma função, que englobe tanto os 
dados antigos como os novos, mas será possível encontrar uma regra, que liga os dados anteriores aos novos e faz aparecer os dois, como derivaçōes da mesma regularidade natural.

Daqui infere-se que não existe uma fórmula ,que tenha a propriedade procurada, não se trata tampouco de uma impossibilidade real, pois poderia ser que alguém deparasse com a fórmula correcta.

Por conseguinte, não tiveram êxito os nossos esforços, no sentido de encontrar um enunciado verificável equivalente ao princípio de causalidade, como as nossas tentativas de formulação conduziram a proposições aparentes ${ }^{22}$.

5.3. O princípio da causalidade não nos comunica directamente um facto, por exemplo, a regularidade natural do Universo, senão que representa uma exigência ou necessidade, uma prescrição para procurar a "regularidade» ao descrever os acontecimentos mediante leis.

Segundo Schlick, aquilo que a teoria dos quanta nos ensina será o seguinte: o princípio de causalidade, estabelecido a partir das relaçóes de indeterminação:

$$
\Delta p x_{i} \cdot \Delta x_{i} \geq 1 / 2 h-\hbar(i=1,2,3),
$$

será inútil ou destituído de finalidade e impossível de cumprir-se. O princípio de incerteza parece fornecer uma prescrição contrária ao princípio de causalidade.

O princípio de causalidade não é um "postulado", no sentido em que este conceito ocorre aos filósofos anteriores. Aqui surge, como norma física, a que nos deveremos ater em todas as circunstâncias. As próprias leis da natureza decidem sobre os limites da utilidade e é nisto que reside a novidade da situação.

Cada postulado pode ser limitado por uma contraprescrição, haurida da experiência, isto é, pode ser reconhecido como inútil e/ou abolido. A validade das leis

${ }^{22}$ Cf. M. Schlick - «Die Kausalitaet in der gegenwartigen Physik», in: Naturwissenschaften, 150-151. 
da natureza e da causalidade não repousaria senão na sua "confirmação».

Pelo pensamento de Schlick, só poderemos verificar a sua confirmação, a utilidade da sua prescrição e não temos o direito de falar da verdade.

A relação de Heisenberg constitui uma lei natural, revestindo, como tal, o carácter de uma indicações ou orientações. A rejeição do determinismo não pode ser aceite como prova da falsidade de um determinado enunciado, mas apenas ilustração da inutilidade de uma «norma».

As leis da natureza não são, na linguagem da lógica simbólica, implicações gerais, dado que não podem ser verificadas para todos os casos, mas são prescrições de comportamento, para o pesquisador situar-se dentro da realidade e encontrar proposiçóes verdadeiras, preparando-se para determinados acontecimentos.

A rejeição do determinismo pela física moderna não significa nem a falsidade, nem a carência de sentido de um determinado enunciado, concernente à natureza, mas a inutilidade daquela prescrição que, na qualidade do princípio de causalidade, indica o caminho para toda a indução e para toda a lei natural. A inutilidade do princípio de causalidade, segundo Schlick, é demonstrada com aquela certeza, que caracteriza a «experiência física» da pesquisa actual ${ }^{23}$.

\section{Regularidade estatística}

O princípio de causalidade incita-nos a construir funções a partir das observações passadas, funções essas que poderão conduzir-nos a fazer novas «previsôes».

Naturalmente que o princípio de causalidade poderia ficar de pé, mesmo que a prescrição conduza ao êxito, tivesse um teor completamente diverso. Esta última não é suficiente para estabelecer o conceito da causalidade, mas representa uma aplicação mais restrita e especial.

\footnotetext{
${ }^{23}$ Cf. Ibidem, 153-156.
} 
Constatamos, na natureza, através de séries muito longas de observações, que um acontecimento A, em média, é seguido numa percentagem de noventa e nove porcento dos casos distribuídos irregularmente, sem que se pudesse encontrar a mínima causa, que fosse capaz de explicar tal desvio.

Com a referência a um tal mundo, diríamos que nele reina muita ordem. As nossas previsóes seriam acertadas numa média de noventa e nove porcento, portanto numa proporção ainda muito maior do que na meteorologia e em sectores da Medicina (PET e a telemedicina). Uma vez que ocorre A, esperamos com muita confiança $B$ e preparamo-nos para isto.Será importante considerar que uma lei estatística, onde quer que na ciência deparemos com ela, é entendida como sendo uma espécie resultante de dois componentes, na medida em que se decompõe a causalidade imperfeita ou estatística numa rigorosa regularidade natural.Assim, na teoria cinética dos gases, procuram-se descrever as propriedades do gás, em termos microscópicos, sob as paredes do recipiente que o contém.. A variação total da quantidade de movimento, por segundo, é a força exercida sobre as paredes pelo gás. Este exerce uma pressão sobre o recipiente, porque as moléculas do gás colidem com as suas paredes ${ }^{24}$.

No cálculo, inicia-se pelo valor da seguinte equação:

$$
N / V \cdot A v_{x 1} \Delta t
$$

Finalmente, escreveremos a expressão das moléculas em termos da velocidade quadrática:

$$
\mathrm{P}=1 / 3 \frac{N}{V} m\left(v^{2}\right)=2 / 3 \frac{N}{V}\left(1 / 2 m v^{2}\right) \text { med. }=2 / 3 \cdot n\left(1 / 2 m v^{2}\right) \text { med.; } n \frac{N}{V}
$$

A pressão é proporcional ao número de moléculas por volume unitário e proporcional à energia cinética dos gases, que será:

$$
\bar{E}_{k}=3 / 2 \cdot R / N_{A} \cdot T=3 / 2 K \cdot T
$$

\footnotetext{
${ }^{24}$ Cf. M. Schlick - «Meaning and Verification», in: The Philosophical Review, 45 (1936) 240260.

${ }^{25}$ Cf. H. S. Irk - Matemáticas superiores aplicadas a la Quimica y a la Fisica, tradução do alemão, Barcelona, Manual Márin, 1948, 37-67.
} 
A energia cinética translacional total de moles de um gás, que contém moléculas será:

$$
N_{K}=N \bar{E}_{k}=3 / 2 N \cdot K \cdot T=3 / 2 v R T \quad 25
$$

Não obstante, a distribuição das partículas individuais e dos seus estados supõe-se ser um estado momentâneo irregular. Da combinação dos dois pressupostos resultam, entretanto, as leis macroscópicas dos gases, como a regularidade imperfeita do movimento de Brown:

$$
\left(x^{2}\right) \operatorname{med}=\frac{R T}{3 \pi \eta \mathrm{aN}_{\mathrm{A}}} \cdot t
$$

Por outras palavras, não nos damos por satisfeitos com uma lei estatística,que acabamos de considerar e a representamos como mescla de rigorosa regularidade natural e total ausência de lei. Quando haveríamos de afirmar que não existe regularidade alguma, que, portanto, os eventos $\mathrm{A}, \mathrm{B}, \mathrm{C}, \mathrm{D}$ são totalmente independentes um do outro.Evidentemente em uma série muito longa de observações, cada uma das séries a ser constituída de diferentes acontecimentos por permutação, ocorre em igual medida de frequência.

Uma tal distribuição dos acontecimentos costuma-se denominar distribuição, segundo as leis da probabilidade. Onde existe tal distribuição, falamos de uma interdependência dos acontecimentos, ou seja, afirmamos que estes não estão reciprocamente ligados pelo «nexo causal».

Segundo o que Schlick expôs, esta concepção constitui não só um sinal de ausência de regularidade pela lei natural, como também por definição se identifica com ela. Logo, a distribuição das probabilidades é pura e simplesmente a definição de desordem completa.

Em razão disto, não posso, de maneira alguma ,aderir à posição de Reichen158-160.

${ }^{26}$ Cf. M. Schlick - «Die Kausalitaet in der gegenwartigen Physik», in: Naturwissenschaften, 
bach, que acredita deve falar de um princípio da distribuição, conforme as probabilidades, como pressuposto de toda a pesquisa da natureza, princípio este que, juntamente com o da causalidade, constituiria a base de todo conhecimento de ordem física ${ }^{26}$.

\section{Conclusão}

A visão de Schlick, sobre a "causalidade», é determinada pela influência do neopositivismo lógico. O princípio de causalidade fundamenta-se na possibilidade dos fenómenos físicos. A «previsibilidade» é o centro da regularidade das leis da física.

Trata-se, pois, de uma «visão» que não considera o fundamento, nem o enunciado metafísico da causalidade. Naturalmente, a consideração da "causalidade» surge como um enunciado físico.

A indeterminação não diz respeito às coisas constatáveis experimentalmente.E stas, poderemos tratá-las exactamente, atendendo às condiçôes de experimentação.

De facto, a indeterminação diz respeito apenas às imagens conceituais, imagens essas com as quais acompanhamos os factores físicos.

Segundo Schlick, o estado actual da Física Atómica e Nuclear não justifica a introdução de um conceito metafísico de indeterminação, da mesma forma não justifica especulaçôes sobre o chamado problema da liberdade da vontade, mesmo com o referido conceito.

A ciência física demonstra-nos que o universo físico não é inteiramente determinado. Daqui se segue naturalmente:

que o indeterminismo tem razão e, portanto, a Física não contradiz a afirmação da liberdade da vontade;

que a natureza, por não ser governada por uma causalidade fechada, deixa lugar para a intervenção de factores espirituais. 
Para Schlick, a Metafísica, de épocas anteriores, cometeu certos erros que retornam agora, onde faltam motivos diversos. Se o determinismo tiver razão, então não há nada que justifique o facto de propor uma acção. Mas, segundo o pensamento de Schlick, as nossas acções e os nossos propósitos obviamente só têm sentido na medida em que o futuro é por eles determinado Mas, será necessário dizer que ,quer o determinismo,quer o indeterminismo, implicam duas formas de causalidade, (a actual e a potencial), em virtude do erro nas medidas, segundo a Mecânica Quântica. A formulação do indeterminismo foi fundamental para uma nova leitura neopositivista, a qual passa por uma análise lógico-simbólica. Naturalmente, segundo as posições de Schlick,é possível uma fundamemtação da causalidade pela sintaxe lógica, sem descorar o sentido gnoseológico do mesmo, dado que o aspecto ontológico não tem qualquer sentido segundo o neopositivismo lógico.

\section{Bibliografía}

Ayres, F. (1991). Cálculo Diferencial e Integral, tradução do inglês, S. Paulo, McGraw Hill.

Borges De Meneses, R. D. (2002). «Teoria do Juízo em Kant», in: Humanistica e Teologia, 23.

- (2005). «Determinismo e Indeterminismo:uma ponte entre a física e a filosofia», in: Estudos Teológicos, 12.

FEYNMAn, R. (1980). La nature de la physique, tradução do inglês, Éditions du Seuil.

Glinka, N. (1987 ). Quimica Geral, tradução do russo, 1 volume, Moscovo, Editora Mir, 29.

Heisenberg, W. (1958). Die physikalischen Prinzipien der Quantentheorie, Mannheim, Bibliographischen Institut.

HuAnG, K. (1987). Statistical Mechanics, second edition, J. Wiley and Sons, New York

IRK, H. S. (1948). Matemáticas superiores aplicadas a la Quimica y a la Fisica, tradução do alemão, Barcelona, Manuel Marín.

Kudriávisev, L. D. (1983). Curso de Análise Matemática, 1, tradução do russo, Editorial Mir.

Matveyev, A. N.; Landovittz, L. F. (1966). Principles of Electrodynamics, New York, Reinhold Publishing. 
SCHLICK, M. (1931). «Die Kausalitaet in der gegenwartigen Physik», in: Naturwissenschaften, 19, Berlin.

- (1932). «Positivismus und Realismus», in: Erkenntnis, 3.

- (1934). «Ueber das Fundament der Erkenntnis», in: Erkenntnis, 4.

- (1936). «Meaning and Verification», in: The Philosophical Review, 45.

SiEgel, C. L. (1965). Curso de Mecânica Celeste, tradução do alemão, Lisboa, Fundação Calouste Gulbenkian.

STARZHINSKI, V. M. (1985). Mecânica Teórica, tradução do russo, Moscou, Editorial Mir.

Synge, J.; Griffith, B. A. (1960). Mecânica Racional, tradução do inglês, Rio de Janeiro, Editora Globo.

Tipler, P. A. (1981). Física Moderna, tradução do inglês, Rio de Janeiro, Editora Guamabara, 1981.

Recibido:18/06/2009

Aceptado: 5/09/2009 